\title{
Analysis and thinking on current situation and training strategy of professional teachers in secondary vocational education
}

\author{
Yuan Gao \\ Institute of Adult Education \\ University of Yangzhou \\ Yangzhou, Jiangsu Province, China \\ gaoyuan@yzu.edu.cn \\ Qiuping Chen \\ College of Educational Science \\ University of Yangzhou \\ Yangzhou, Jiangsu Province, China \\ qpchen@yzu.edu.cn \\ Jiping Zhou \\ College of Mechanical Engineering \\ University of Yangzhou \\ Yangzhou, Jiangsu Province, China \\ jpzhou@yzu.edu.cn
}

\author{
Yimin Li \\ College of Mechanical Engineering \\ University of Yangzhou \\ Yangzhou, Jiangsu Province, China \\ yzjxlym@163.com \\ Yongfa Qin \\ College of Mechanical Engineering \\ University of Yangzhou \\ Yangzhou, Jiangsu Province, China \\ yzqyfa@163.com
}

\begin{abstract}
As the state has made great financial investment and showed strong policy support for secondary vocational schools, vocational education development has entered a new historical stage. An in-depth research has been made about the present status of professional teachers in secondary vocational education field in China, which found that some problems still exist in the teachers condition that adverse to the development of secondary vocational education. Through analyzing the status of professional teachers and their professional ability, relevant countermeasures will be put forward in terms of training professional teachers in those schools in order to provide reference for teaching stuff construction of vocational education in China.
\end{abstract}

Keywords-Secondary vocational; education; professional teachers; training

\section{INTRODUCTION}

Secondary vocational education is to develop application-oriented, skilled talents in the process of production in companies. It covers two key words, "education" and "occupation", which makes it become a kind of cross-border education: across the territory of enterprises and schools, across the boundaries of working and learning; that is to say secondary vocational education spans the original domain of occupation and education category. This kind education is clearly marked with the stigma of vocational education, for occupation and education both have their own law and rules, the essence of vocational education's trans boundary requires the fusion of career goals and educational goals.

In recent years with vigorous investment and policy support for the secondary vocational school of this country ${ }^{\text {[1- }}$ ${ }_{2]}$, the professional teaching stuff condition has been improved obviously, but there still exits great difference of teaching stuff condition among the key vocational schools, general vocational schools, vocational schools in center cities and the county-leveled vocational schools, vocational schools in developed regions and underdeveloped regions. Therefore, there is a need to strengthen the teaching stuff construction of professional teachers in those schools to cultivate skilled talents with high quality of production to meet the urgent need so as to ensure the sustainable development of the social productivity. The author had the honor to take charge of the undergraduate teaching stuff mechanical technology resources development projects of Ministry of Education and Ministry of Finance, and in the development of making standards secondary vocational school professional teachers who major in mechanical technology, the author has conducted extensive research on the status of those professional teachers in secondary vocational schools and gained some understanding and thinking.

\section{THE STATUS ANALYSIS OF PROFESSIONAL TEACHERS}

In order to guarantee validity and pertinence of the standards for professional teachers, this project team mainly adopt literature method, social investigation method, observation method and discussion method at the early stage, using Chinese HowNet (CNKI), Baidu library Google Scholar and other network databases and China machinery Industry Association official and foreign well-known websites as search platform. Methods like questionnaire survey method (including student questionnaires, teacher questionnaires and machinery enterprises questionnaire), access method (visiting secondary vocational schools and mechanical employer in different regions, provinces ), tests, observation and exchange with national, provincial backbone 
teachers on machinery and other forms will be adopted to conduct a through investigation about education status of professional teachers in the secondary vocational schools and on the role of socialization of personnel training. According to investigation statistics of professional teachers' basic situation and their professional competence, it is not hard to conclude that with the country's stronger investment in vocational and policy support, teaching stuff in our professional and vocational schools has made some significant improvement and also a number of qualified professional teaching group emerged who are to train and cultivate talents. But even so, on the whole there still exists some problems that adverse to the development of secondary vocational education on the teaching stuff level. And these problems are as followings:

\subsection{Adverse echelon of professional teachers, the overall number is still insufficient}

Professional teachers in vocational schools are mainly young, of which young and middle-aged teachers aging under forty-five account for $80 \%$, and teachers of this age level has become the backbone of each school. Ratio of Teachers aged form 51 to 60 years in all types of schools is generally low, and mostly the ratio does not exceed $10 \%$. For state-level key vocational schools or vocational schools in economically developed areas, their overall teaching stuff level is better, but because of its larger enrollment the gap between teachers and students is still large. According to state student-faculty ratios 1:20 calculation, the studentfaculty ratio in these schools is generally above 1:25, even some individual schools is up to $1: 45$.For the long run, teachers has generally endured huge workload and pressure, and gradually the teachers will lose passion for work, and even worse, some may produce disgust or lost basic sense of responsibility as a teacher; For the vocational schools in the economically less-developed areas, according to research data, despite of the relatively low ratio, the reasons are analyzed including: Firstly, there are difficulties with enrollment, that is, these schools are difficult to complete basic annual enrollment targets; Secondly, it means that the school's faculty is relatively weak and the faculty status in some schools is even difficult to meet the basic requirements of the operating conditions.

\subsection{Technical graduates in vocational school takes a small proportion}

According to the survey, the existing professional teachers in secondary vocational school are mostly from the ordinary university and ordinary normal university, but the number of graduates from technology normal schools is relatively small, and nearly half of the teachers in vocational schools have not learned the subject of professional vocational education and occupational psychology, and only about $20 \%$ of the professional teachers have systematically studied these two subjects. The reason behind this is that the source of professional courses teachers of vocational schools is complicated. Some of them are graduates of normal colleges, some normal universities, and some are vocational college students and some are even stuff who has certain technical titles transferred from enterprises and other institutions. They mainly only have some scattered perceptions on vocational education, lacking a better theoretical knowledge. In this way, it is inevitable that the teachers will exits the lack of theoretical knowledge of profession education in the secondary vocational schools. Although they had received continuing education training once or several times before or after work, the training does not have a very strong pertinence and is not systematic. Facing the huge numbered vocational students who are left after selected by ordinary high school, professional teachers need to know how to effectively guide the students' career, cultivate students' good professional ethics, excavate the potential ability of students, etc., in order to do that it is so urgent for majority of professional teachers to be unceasingly enterprising in their career, otherwise, the phenomenon that training quality of secondary vocational schools is not high is inevitable.

\subsection{The teachers' education qualification and teachers' structure needs to be further improved}

As it can be seen from the professional teachers' qualifications and professional titles: the qualifications of professional teachers mostly have bachelor degree; intermediate titles accounted for nearly half of all; the proportion of highly educated and highly titles is significantly low; and the proportion of the high-skill-leveled technicians only accounts for one-third. As in recent years the country has been promoting the "Bachelor" project in secondary vocational and technical schools vigorously, it should be said that the teaching group construction of each school has made remarkable achievements and the proportion of theory course teachers with bachelor's degree has been increased significantly. But in fact, many vocational schools do not have the corresponding professional teachers for specialized courses, some teachers teaching general knowledge course are asked to teach specialized courses instead; therefore, in some vocational schools the prevalent phenomenon is that teachers for general knowledge course are more than the teachers for professional courses; the number of teachers for professional theory courses and professional basic courses is significantly larger than that of practical guidance teachers, resulting that the faculty structure is obviously unreasonable.

\section{4 "Double Type" teachers who can teach both professional courses and Practical Guiding courses are in a small proportion, and there is still a gap with the proportion required by Ministry of Education}

A great many surveys show the experience of corporate practice is considered to play a crucial role for vocational education, for extensive practical experience enables teachers to have good practical ability in assisting students to develop the required operational capability in a better way. At present, some of professional teachers in secondary vocational schools graduated from vocational schools and normal engineering colleges. Although they have professional theory in a certain level, generally they lack practical corporate experience, knowing little about the 
enterprise's production, having lower operating ability and they cannot combine with practice in teaching, most of which are impractical. Other professional teachers are graduates of technical secondary schools or secondary vocational schools. Although they have better practical operational ability, they are in a relatively low theoretical level, despite the fact that many teachers get bachelor's degree through adult education in the process of improving teachers' "undergraduate rate "in each school. The truth is that their knowledge structure does not really reach the theoretical level of undergraduates. From the current status of teaching group in secondary vocational schools, the quality constitute, their experiences, practical skills of existing teachers are insufficient to meet the requirements of reform and development innovational education.

\section{THE ANALYSIS FOR THE ABILITY OF PROFESSIONAL TEACHERS}

Teachers' professional ability of secondary vocational school is the basis of skilled personnel training [4-6]. Professional ability involves professional cognition, professional teaching design, teaching implementation, training practice organization, class management and education activities, education teaching and evaluation, communication and cooperation, and other several aspects such as teaching research and professional development. In the study of secondary vocational teachers' professional ability, we have carried on the questionnaire survey including total 90 questions covering ten aspects including basic ability, designing and developing professional teaching plan, teaching material designing teaching plans, teaching management, teaching organization , assessment of teaching effect, review and evaluation of teaching plan, professional self-development and professional research and development. The statistical results for each question would be expressed as a percentage based on the number of papers, reflecting the professional teachers' overall professional ability in the teaching process. The statistical results are shown in figure 1 ( $a, b, c$, etc on behalf of the related issues).

The figure shows that the teaching methods and teaching means are relatively lagging and the capability to master and apply the professional teaching materials should be improved among the existing professional teachers in secondary

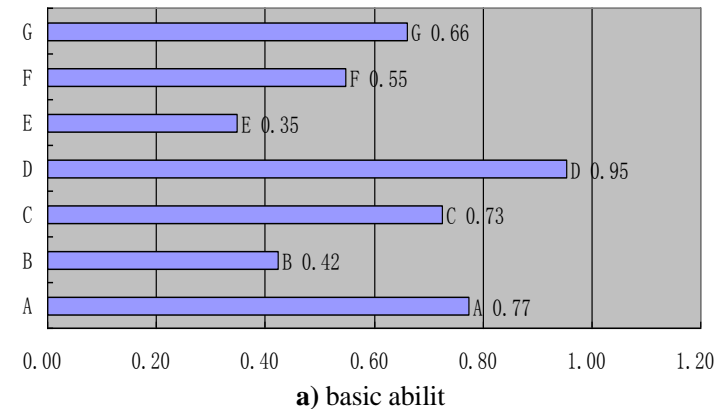

a) basic abilit vocational school. It can be learned from the survey that some professional teachers lack of grasp of the teaching material and creative ability only using the teaching material to teach. Teaching effect is obviously that the teachers teach according to the textbook, but the students read and copy the textbook. The reasons for the kind of situation are mainly two as follow; one is that the teachers don't want to get this discipline teaching as their own professional development direction, being perfunctory, impatient, lacking inquiring mind. The other reason is that because there are teachers who are specialized in other majors, teaching only superficial knowledge for they lack professional systematically learning, which results in a shallow understanding of teaching material. Other part-time teaches will not be able to devote more time to this subject of lessons and teaching because of not having enough time and energy. Even those professional young teachers often apply the teacher's methods acquired in their college to the teaching of secondary vocational schools. They are not able to correctly understand the differences between the two because of lacking of systematic learning and training, resulting that the actual teaching effect is not ideal.

As far as the employment situation of students in colleges and universities, the graduates to secondary vocational school are also belongs to the good students. They generally mastered the basic theoretical knowledge of related subjects, but they lack teaching experience and don't know much about the discipline of the teaching process. Even some teachers take the role of being a teacher even before that they understand what is teaching and how to teach. This kind of undesirable teaching starting point has something to do with the unhealthy teaching habits forming in the teaching process. Young teachers have common problems in teaching including: unreasonable teaching organization and teaching arrangement; insufficient teaching information; little relevance of theory and practice; single teaching method; not making full use of modern teaching means to show the difficult key problems in the teaching contents and failing in mobilizing the students thinking and learning motivation. Some teachers can't get away from the disadvantages of subject teaching with cramming method and mainly adopt lecture teaching methods, which cause a decline in students' learning interest.

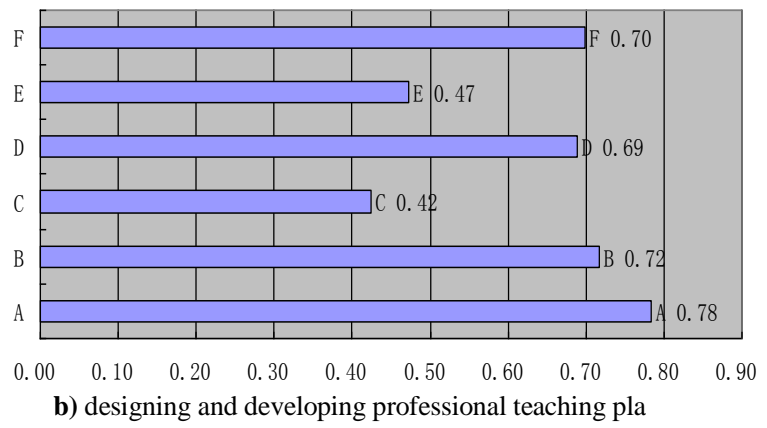



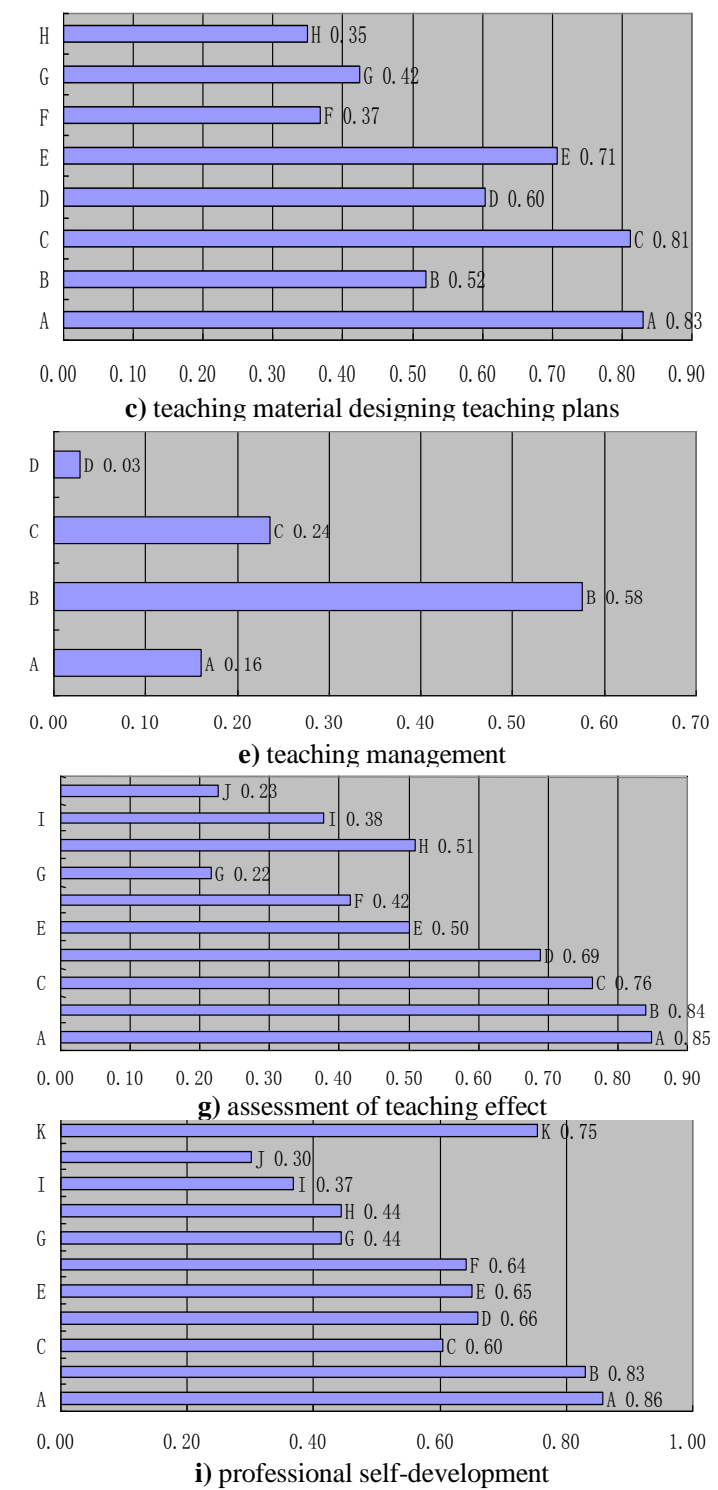
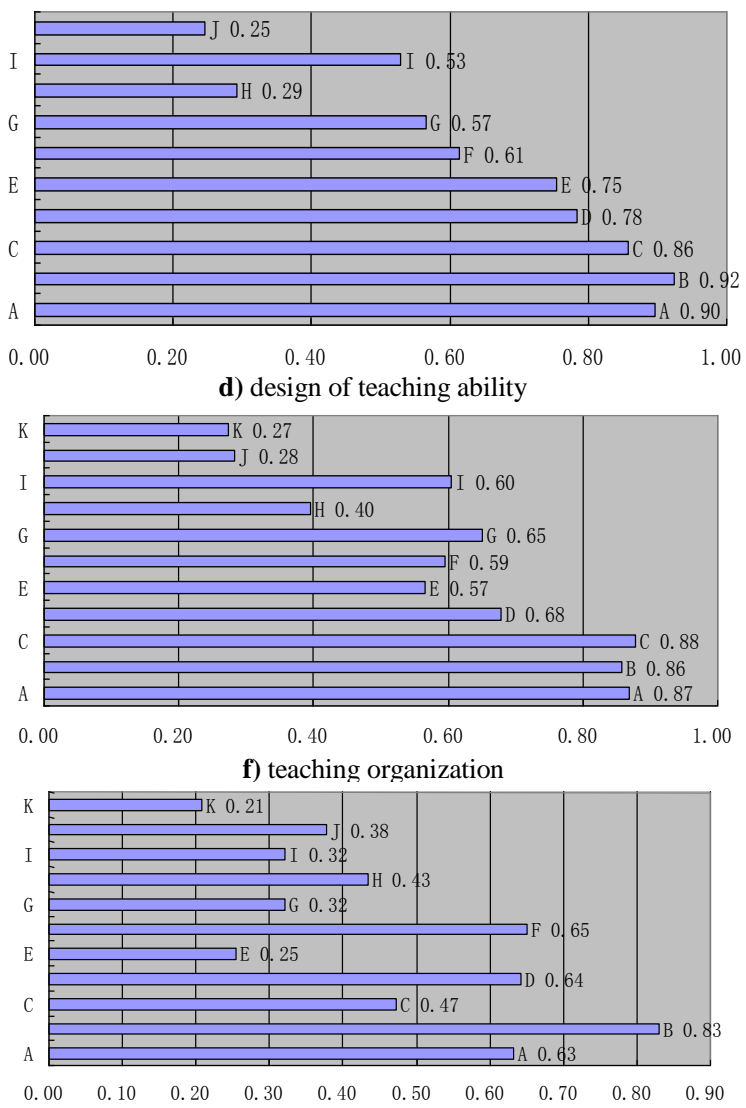

h) review and evaluation of teaching plan

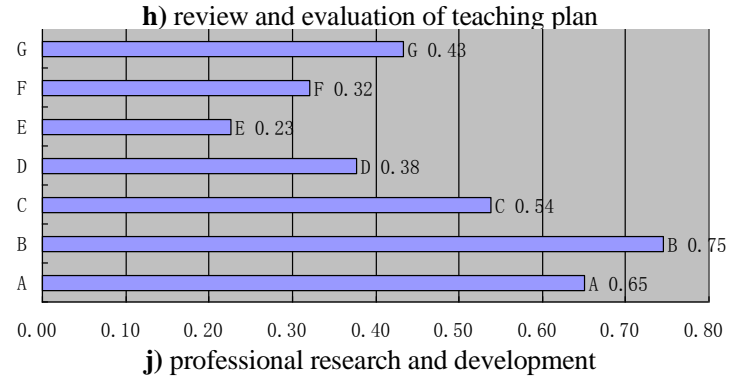

Figure 1 Investigation and statistical analysis on Professional teaching ability

IV. SOME THINKING ABOUT PROFESSIONAL TEACHER TRAINING OF SECONDARY VOCATIONAL SCHOOLS

\subsection{Putting the moral education work in the first place,} actively cultivating and practicing the socialist core values, comprehensively promoting quality education

Insisting on education and highlight professional ethics education with emphasis on the integrity and dedication., a qualified professional teachers in a secondary vocational school should not only have strong professional education teaching ability, but also can carry on the channel to the student thought and psychological; More importantly they should have noble professional ethics in the thoughts, love of vocational education business and have a professional attitude and dedication.
Professional teachers in a secondary vocational school not only need to have "double certificates" ,professional teachers' qualification and professional skill, and "double skills", imparting professional knowledge and the operation skills. More important is that our professional teachers can undertake the important task of "education", which is not only the requirements for professional teacher visible, the surface of the knowledge and skills, but also higher requirements for professional teachers' core value system which is deep, hidden, invisible, such as self-concept, attitude, values and motivation, and its own characteristics, etc., all of which will determine whether or not a professional teacher really can become a qualified and outstanding professional technical teachers in a secondary school. Currently, secondary vocational schools are busy with school development and research work, or advocating 
"student-centered ", ignoring or reducing the attention to teachers' team and the attention to research of launching core value system of professional teachers, and establishing and carrying out effective implementation, which will have serious blocking effect for the sustainable development of the vocational schools. Therefore, how to proceed from the teachers' core value system elements and the core value of team in secondary vocational schools setting up a complete core value system and operational mechanism, effectively promoting the scientific development of the vocational schools need further research and strengthen this work.

\subsection{Further deepening the reform of the education teaching}

Professional teachers in secondary vocational schools in China are tend to be young. Young teachers have become the main stream in the school teachers' team. From the survey data statistics, the results is that $80 \%$ of young and middle-aged teachers is under the age of 45 , who bear the more onerous task of teaching. However, young teachers lacking teaching experience is hard to find time to update, supplement, digest, and improve their knowledge for such heavy teaching tasks, and they even don't have time to study and improve the teaching. Therefore, most of the young visiting teachers are urgent to use a short period of time to enrich and improve themselves, especially wanting to strengthen their practical ability in enterprises and widening their knowledge in relative universities. Hence, teaching ability of young teachers remains to be further improved, helping them to have good start in their work by making them successfully transform from the educated - "students" to the educators as soon as possible. Therefore, strengthening young teachers' teaching ability through the training paving them a professional development path of "from students to teachers, from teacher to top teacher", has become the heartfelt wishes of teaching directors and leaders in many secondary vocational schools.

By enhancing the professional practical experience of professional teachers, guiding them actively explore various effective teaching methods in the teaching process, such as case teaching, project teaching, behavior guiding teaching, task driven teaching method, heuristic method and discussion-based teaching method and so on, making the students, passive knowledge receiver, into active learners, in this way learning initiative and creativity can be enhanced in the whole teaching process. Similarly, in the course of training skills teaching, also the teachers should change from relatively rigid teaching method to letting the students learning knowledge form skills, cultivating innovative consciousness and emotional labor in the process of practicing on hand. To inspire the students learning enthusiasm and creativity takes fully advantage of the training course in the implementation of quality education. Let the student have fun in the training class so as to motivate students to have higher training learning enthusiasm. This requires that the professional teachers are able to develop curriculum and skills and other training, and teachers of different layers have different requests: the teachers on duty should focus on studying, under the guidance of backbone teachers, they should combine all kinds of teaching and researching activities together, making teaching design and practice, comparative analysis, finding out gap, improving their teaching behavior, the practice teaching skills; the requirements for the backbone teachers is that they should focus on implementing to improve teaching behavior in view of the preset teaching design and teaching behavior and do timely adjust effectively based on the development of the teaching process.

\subsection{Strengthen the training of the professional teachers' practical ability and professional skills, cultivating professional teachers of "double division type"}

A professional teacher should design the entire teaching process based on the student grasping the actual working process ${ }^{[7]}$ and implement the teaching process on the basis of the working process of such a person's mind of information - decision - planning - implementation - check. A qualified professional technical secondary school teachers should attach great importance to practice and practice teaching and should be "all-rounder" and "generalist", not only mastering the professional theories, but the comprehensive practice ability. A professional teacher becomes a real "double division type" one through crossborder education and training from the education theory, the education practice, and professional theory to the professional practice.

Today is the age of rapid development in professional skills, constantly updating professional knowledge, fast rhythm of enterprise production equipment, more requirements are need for professional teachers who have to timely grasp the most forefront professional and technical knowledge, understand the principle and use method of advanced instruments and equipment, make timely and effective adjustment of teaching process to meet the applicability of the students for future jobs.

\subsection{Push forward the training mode of work-integrated learning, school-enterprise cooperation}

Training of professional teachers' ability should be strengthened in the production practice and social practice through the work-integrated learning closely linked with the enterprise. School and classroom, as the center of traditional personnel training mode should be informed. Professional teachers develop high-skilled talents who meet the needs of employment market and the requirements of the job skills by obtaining professional qualification certificate and professional practice in the enterprise production line and going back to the secondary vocational schools

Vocational education development concept of "Workintegrated learning, university-enterprise cooperation" has gradually enjoyed popular support. Establishing excellent teaching team between colleges and enterprise is an important guarantee of achieving this goal. However, many practical difficulties exist in the construction of the team at present: one is that the construction of teaching team has a trend of piecing together and labeling. Team work is temporary, piecing together, even for the sake of application projects and imaginary conception. Such teams are in lack of scientific basis, low degree of organization of organic, lack 
of value orientation alignment, independent members, team spirit and cohesion. More importantly is that members employed are relative less from industry and enterprise, whose structure is unreasonable and team practice is poor. Secondly, obstacle exits in the running mechanism. If funds, personnel, system guarantee, mechanisms have shortcomings at the school level, level within the team and external associated with enterprise level, which can make operation impeded and even gave up halfway. Thirdly, in the current evaluation system lacking of a sound evaluation mechanism, there exist stressing individual, brushing over collective; stressing Leadership, brushing over members; stressing output, brushing over run ${ }^{[8]}$. The team cohesion, cooperation and innovation enthusiasm are reduced. How to crack the predicament is subject to the further exploration of the effective management mechanism.

In short, the secondary vocational school teachers' professional training must reflect the times characteristics ${ }^{[9]}$, which adapts to the demand of skilled personnel training for industry development and professional technical development. "Professional teachers" and "engineer" double quality requirements should be cleared, emphasizing professional talents' knowledge and ability, teaching knowledge and ability for teaching specialized courses, practice teaching. The teaching ability should be strongly highlighted, especially the ability to impart knowledge especially as a professional teacher in secondary vocational schools in the face of secondary vocational students' learning, understanding. Strengthening professional practice ability is the priority for training skilled talents, being the starting point of the enterprise of choose and employ persons. Professional teachers must have the corresponding professional practice ability so as to adapt to the requirement of cultivating skilled talents. More is highly required for professional teachers along with the development of the level of vocational education especially. The teacher required not only need knowledge of theory combining with practice teaching ability, also need professional teaching ability to master the high-tech development and application in the industry at any time. Putting forward this ability also makes secondary vocational education teachers' professional knowledge in our country deeply advance and improve.

\section{ACKNOWLEDGEMENT}

This research was financially supported by the undergraduate teaching stuff mechanical technology resources development projects of Ministry of Education and Ministry of Finance

\section{REFERENCES}

[1] CPC Central Committee and State Council. On the decision of deepening education reform and recommending quality education[R].1999.

[2] WuQidi. The speech of teachers work conference on secondary vocational education in the nationwide [Z].2007.4.22.

[3] Zhang Fengling. The issue of vocational education teachers construction and countermeasures-The case of study Chongqing[J]. Journal of Chongqing College of Electronic Engineering. 2013. (5) : 12-15.

[4] Zhu Xinxin, Zhang Li zhen. Analysis of teachers professional development standard in the nation and abroad [J]. NAEA Journal.

[5] Training and Development Agency for Schools. Professional Standards for Teachers:Why Sit Still in Your Career [EB/OL].http://www.tda.gov.uk/teachers/ professionalstandards. 2007-1222.

[6] Chen De yun. Refer of teachers professional standards of in the international perspective [J]. Educational Science Research, 2010, (8) :7276.

[7] Jiang Da yuan. On the process systematization of vocational education curriculum development [J]. Xuzhou Institute of Architectural Technology, 2010, (1) :1-6.

[8] Zhang Jinjuan. Building a support system of evaluation of human resources training [J]. Corporate research, 2008 (3).

[9] Shi Weiping. Characteristics of the times and vocational education innovation [M] Shanghai: Shanghai Education Press, 2006. 